\title{
Investigation and Analysis on the Current Situation of the Commercial Bank in China Performing Moral Obligations
}

\author{
Zhuobi LUO \\ Central University of Finance and Economics, School of Marxism
}

\begin{abstract}
The commercial bank plays a vital role in the process of social and economic development. High debt and strong externality determine that it should perform more powerfully in social moral obligations. This paper launched investigations and analysis on the situation of the commercial banks in China fulfilling moral obligations. By collecting the questionnaires of social public and bank practitioners, refining the regulatory data released by the regulatory authorities, analyzing the annual report data publicly disclosed by the commercial banks, comparing the primary data of social responsibility performance of the commercial bank and other industries, it is found that the performance of social moral obligations by the commercial banks in China stays at a reasonable level. At the same time, there are some obvious problems, such as the indifference of moral consciousness, the deviation of ethical behaviors, insufficient governance, and the insufficiency of the security system of moral obligations. Based on China's specific political and economic environment, this paper pushes forward some suggestions to promote the commercial banks in China to fulfill the social moral obligations better.

Keywords: the commercial bank; moral obligations; sense of moral obligations.

Corresponding Author:Zhuobi LUO, research assistant of Central University of Finance and Economics, doctor of School of Marxism, 15110125315, E-mail:cufelzb@163.com, address:No.39 Xueyuan South Road, Haidian District, Beijing
\end{abstract}

DOI: $10.36012 /$ ems.v1i2.1834

\section{The Connotation of Moral Obligations of the Commercial Bank}

$\mathrm{M}$

oral obligations are the moral responsibility that the actor should bear for the behavior and its consequences. The commercial bank's moral obligations mean the commercial bank's liable moral obligations to its actions and outcomes. It is the moral responsibility that the commercial banks should take to investors, customers, business partners, employees, communities, governments and other stakeholders, as well as to the social and natural environment to realize the sustainable development of politics, economy, culture, society, ecology and other aspects while following the operation principles, providing banking products and services, pursuing profit objectives and creating bank value. Moral obligations of the commercial bank include safeguard- ing the legitimate rights and interests of shareholders and treating all shareholders fairly; being people-oriented, attaching importance to and protecting the legitimate rights and interests of employees; operating in good faith, safeguarding the legitimate rights and interests of consumers; fighting against unfair competition, commercial bribery, money laundering, and creating a good market competition order; improving community financial services, promoting community development; caring for social development and supporting social public welfare undertakings; saving resources, protecting and enhancing the natural ecological environment, etc. the commercial bank in China is rooted in the socialist market economy with Chinese characteristics. It was established with the approval of the People's Bank of China and the regulatory authorities. The state-owned holding or participation is the current 
equity structure of major commercial banks. Therefore, the most critical moral obligations of China's commercial banks are to implement the will of the state, implement the government's macro-control policies, abide by the socialist core value system, embody the moral core of socialism to serve the people, and strive to fulfill the requirements of high-quality development in the new era.

\section{The Current Situation of the Commercial Bank Performing Moral obligations}

\subsection{Perspective of Practitioner}

The project group launched questionnaires taking the commercial bank practitioners as the subject. In 2018 and 2019, 393 questionnaires were collected for two consecutive years. The data came from 29 provinces and cities in China. The respondents' age structure: $44.78 \%$ were between $20-30$ years old, $47.07 \%$ were between $30-40$ years old, and $6.87 \%$ were over 40 years old. The gender ratio: $54.71 \%$ for men and $45.29 \%$ for women; the educational background structure: $65.65 \%$ for undergraduates, $21.37 \%$ for masters, $6.62 \%$ for doctors, and $5.34 \%$ for junior colleges.

As shown in the investigation and research on practitioners' view on the current situation of performing moral obligations by the commercial bank, in terms of the national economy and social livelihood, $65.39 \%$ think the development of the commercial bank in recent years promotes the soundness and prosperity of the national economy. $64.89 \%$ think that the bank is playing a positive role in helping the poor and improving social livelihood. 54.45\% think the development of the commercial bank improve the ecological and resource environment. $82.69 \%$ basically agree that banks pay attention to saving resources and protecting the environment in operations. In terms of social ethos and socialist morality, $75.07 \%$ believe that banks pay attention to moral image and play a good role in demonstrating social morality. $77.86 \%$ believe that banks' business activities are people-centered, while $82.19 \%$ believe that banks' business activities reflect the requirements of socialist core values. In terms of the overall evaluation on the social moral level of the commercial bank, $16.54 \%$ think that it is great, while $61.07 \%$ satisfactory.

At the same time, practitioners have relatively obvious negative comments on the current situation of performing moral obligations by the commercial bank. Among all people being interviewed, 23.41\% think that business activities of the commercial bank indulge speculative economy and bubble economy. $19.34 \%$ of respondents believe that the business activities of the commercial bank widen the gap between the rich and the poor. $12.21 \%$ believe that the development of the commercial bank promotes social impetuosity and ag gravates the worship of money. $7.12 \%$ believe that the investment of the commercial bank has worsened the ecological environment. In addition, there are negative comments on the commercial bank by practitioners, such as "capital crush and strong pursuit for profits",

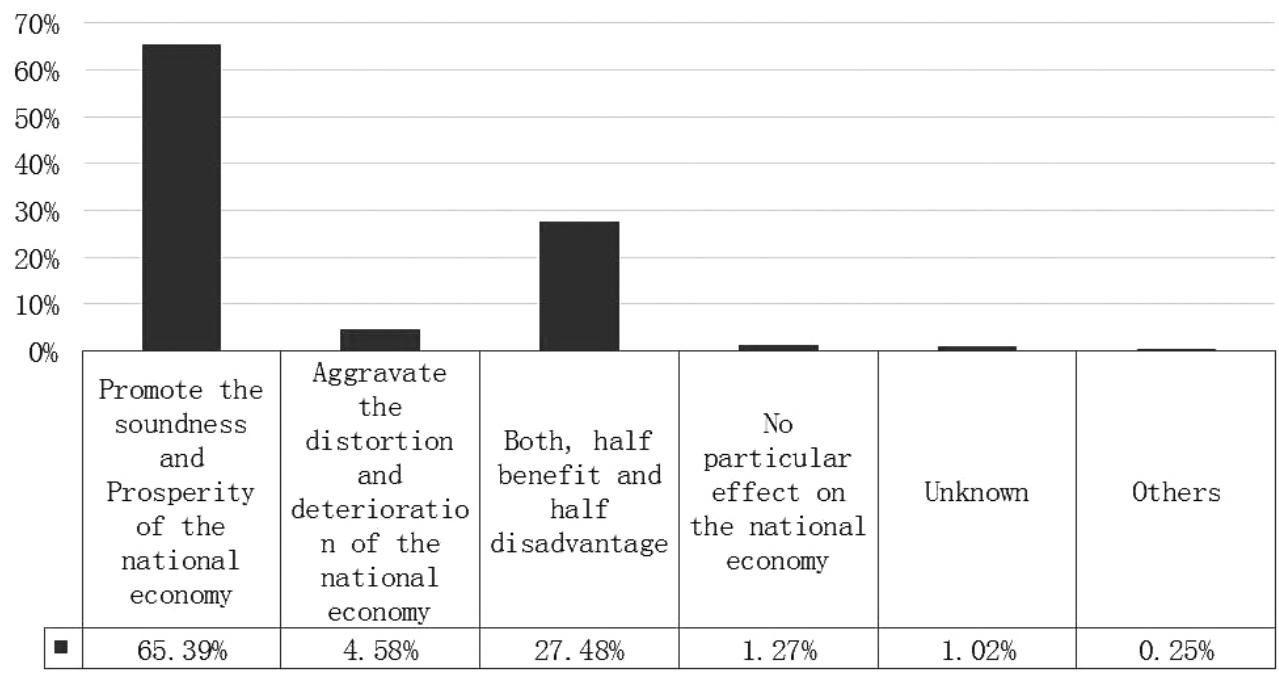

Figure 1. Practitioners' view on "the impact on the national economy of the flourishing commercial banks" 
"hatred for the poor and love for the rich, discrimination in customers and regions", "money worship for adding value to capital rather than serving the people and functional alienation".

\subsection{Perspective of Social Public}

In order to obtain more objective evaluation data, the project group distributed a questionnaire on the image of commercial banks' moral obligations to the public. A total of 2,799 questionnaires were collected, of which 2,429 were valid samples, covering all provinces and cities in China. In the samples, $44.22 \%$ are male and $55.78 \%$ female. In terms of education, $75.96 \%$ are or above undergraduate and $24.04 \%$ are or below junior college. In terms of occupational structure, college students account for $18.6 \%$, teachers $9.67 \%$, employees $9.22 \%$, business owners $6.88 \%$ and civil servants $6.3 \%$.

Regarding the impact of the growth of commercial banks on the national economy and people's livelihood, $48.33 \%$ of the respondents believe that the development of commercial banks promoted the soundness, prosperity, and stability of the national economy. $51.3 \%$ believe that commercial banks played an active role in helping the poor and improving people's social life. $41.05 \%$ believe that commercial banks have improved the ecological environment. In terms of social ethos and socialist morality, more than $40 \%$ of the respondents believe that the business activities of commercial banks have a positive impact on social morality, and more than $50 \%$ believe that the business activities of commercial banks have a good or satisfactory performance in practicing socialist core values and reflecting socialist core morality. For the "overall evaluation of the social morality level of commercial banks", $66.88 \%$ of the respondents think that the social morality level of commercial banks in China is relatively good or excellent.

At the same time, the public also has a considerable amount of negative comments on the current situation of commercial banks performing moral obligations. Among the respondents, $31.86 \%$ believe the development of commercial banks has widened the gap between the rich and the poor. 59.29\% believe that there was client discrimination or regional discrimination in the business activities of commercial banks. $16.55 \%$ believe that the commercial bank was not powerful enough to help the poor and improving people's social life. $17.92 \%$ believe that commercial banks failed to take the initiative to consider others or public interests. $10.86 \%$ believe that commercial banks' development harms social morality, and $9.1 \%$ think that they have deviated from socialist morality and core values to varying degrees. 9.78\% think the environment deteriorated consequently. Also, the public has different degrees of perception of commercial banks' manifestations, such as "capital crush, pursuing profits strongly and serving capital" and "extreme utilitarianism".

\subsection{Perspective of Supervision Department}

The business activities of the commercial bank in China are mainly under the supervision of the People's Bank of China and the China Banking and Insurance Regulatory Commission. The supervisory data and punishment documents issued by the regulatory authorities reflect the fulfillment of moral obligations by the commercial bank in China to a certain extent. This paper collected and sorted out 3,372 administrative penalty cases publicly disclosed by China Banking Regulatory Commission (CBRC) and 36 Banking Regulatory Bureaus from January 1, 2016, to December 2019. Among them, 88 were administrative penalty cases of CBRC, and 3,284 were administrative penalty cases of various banking regulatory bureaus. Also, 2,036 fines were imposed on institutions, 969 on individuals, and 279 on both. The total amount of penalties reached 4.205 billion yuan, while the individuals' fines reached 29.469 million yuan. From the basis of administrative penalty, the number of penalties for violation of credit business is the largest, up to 1,593 , accounting for $49.84 \%$; the number of penalties for bill business is second only to credit business, up to 421 , accounting for $13.17 \%$; the number of penalties for violation of prudent operation principle is 669 , accounting for $21 \%$. In terms of the number and amount of fines, the situation of regulatory penalties for commercial banks in China is still severe. They are faced with major challenges such as preventing and defusing financial risks, controlling the macro-financial leverage ratio, and enhancing the ability to serve the real economy.

\subsection{Perspective of Industrial Comparison}

(1) Return on Equity

The index of return on equity is the percentage of 
net profits and average net assets. It reflects the return on investment of company owners' equity and serves to measure the values created by the commercial bank or other companies for shareholders. According to the data provided by WIND, the average return on equity of the banking industry from 2016 to 2019 is always higher than the average of other sectors in comparison with that of the non-banking sector. The banking industry maintained a return on equity of more than $10 \%$, while that of other sectors fluctuated by $10 \%$. From the perspective of time trend, in recent years, return on equity has been declining in both the banking and non-banking sectors, but the gap between non-banking and it is gradually narrowing. The development of the banking sector is mainly based on the real economy. The service economy is the main melody of the banking sector. However, the banking sector is leading all the way to significantly higher than that of the real economy profit margins, becoming the most profitable industry in the social economy. Banks' profits are mostly transferred from the real economy, which, to some extent, deviates from the primary function of serving the real economy and harms the development of the real economy.

(2) Disclosure of Social Responsibility Report

Since the Shanghai Pudong Development Bank issued the first social responsibility report of China's banking industry in 2006, the release of the social responsibility report of China's commercial banks has gradually emerged. In recent years, major commercial banks in China have issued annual social responsibility reports, and almost all of these reports can be found on the banks' portal websites. The statements are exquisitely prepared, and contents are relatively fully disclosed. Compared with other industries in China, commercial banks attach relative importance to the disclosure of social responsibility reports, and the revealed information, such as the number of social donations and the value of social contributions per share, is relatively complete. At the same time, by comparing the content in reports on social responsibility of commercial banks in China and other major countries, we find that The fulfillment of social moral responsibility by commercial banks in China is mainly in response to the call of national policies. The responsibility reports released in China are mostly accumulation and piling up of events related to social moral responsibility carried out in the same year. The reports lack systematic and long-term planning and fail to form endogenous, long-term goals and plans for social responsibility.

\section{(3) Social Contribution Value Per Share}

Social contribution value per share was created for the company's contribution to society with the company's equity ratio of the total. Its primary connotation is to increase the value created by the company for the country, employees, creditors, communities and other stakeholders in a year based on the basic earnings per share, and deduct additional social costs caused by environmental pollution to calculate the added value per share created by the company for the whole society. In 2018, there were a total of 3,617 listed companies in China, and 131 among them disclosed their social contribution per share, accounting for about $3.62 \%$. Divided by industry, the banking industry and the financial industry have relatively high disclosure ratios of social contributions per share, up to $36 \%$ and $22.22 \%$, which indicates that the listed companies in the whole banking industry attach great importance to it the disclosure of social responsibility reports and data.

In terms of the industry average (See Figure 2), the average social contribution value per share disclosed by the financial industry is 4.39 yuan, among which the average amount of the banking industry is 5.80 yuan. The social contribution value per share of the commercial bank is significantly higher than the average values of the financial industry and other in dustries.

\section{(4)Social Endowment}

Social endowment refers to the philanthropic donation to public welfare undertakings such as education, health, and civil affairs through non-profit public organizations or state departments, or to areas suffering from natural disasters and poverty. In terms of the number of companies disclosing social endowment, the manufacturing sector had the largest number of companies (128 companies). In contrast, the financial sector had 34, and 20 of which were banking companies. However, in terms of the proportion of industry disclosure, only $5.59 \%$ of all listed manufacturing companies disclosed the amount of social endowment. 


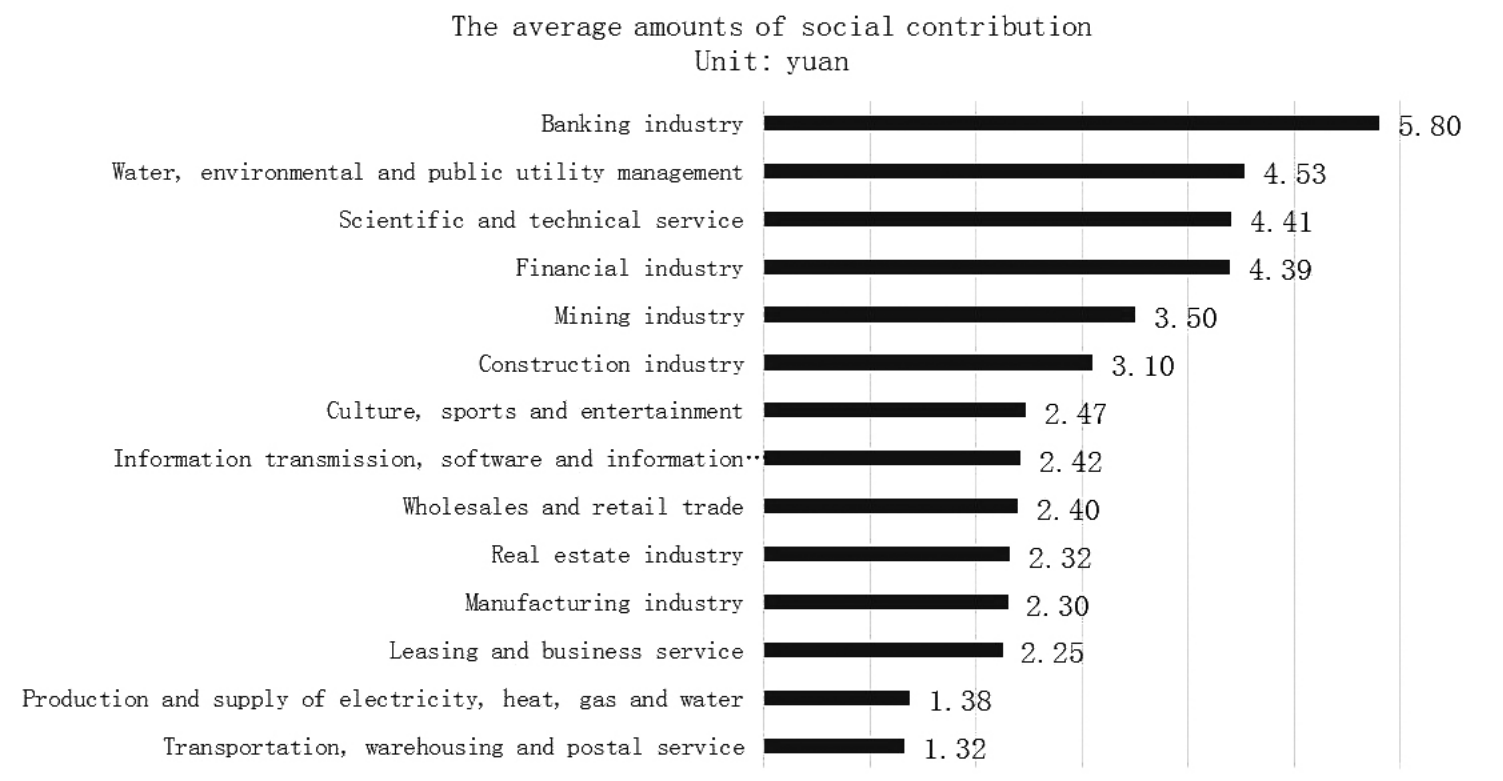

Data source: Manually organize the data disclosed in the social responsibility reports of listed companies

Figure 2. The comparison of average values of social contribution value per share in main industries (2019)

In comparison, $34.34 \%$ of the financial industry, as a whole, disclosed the amount of philanthropic donations. The banking industry accounted for $62.50 \%$ with the first ranking, indicating that listed banking companies attached more importance to the disclosure of social endowment.

The average amount of social endowment in the industry (Figure 3) shows that the average amount in the health and social work industry was the highest, reaching about 85.575 million yuan. The average amount in the financial sector was 36.127 million yuan and in the banking industry, 45,404 million yuan, which is higher than the average amount in the financial sector.

The average amounts of social endowment

Unit: Ten thousand yuan

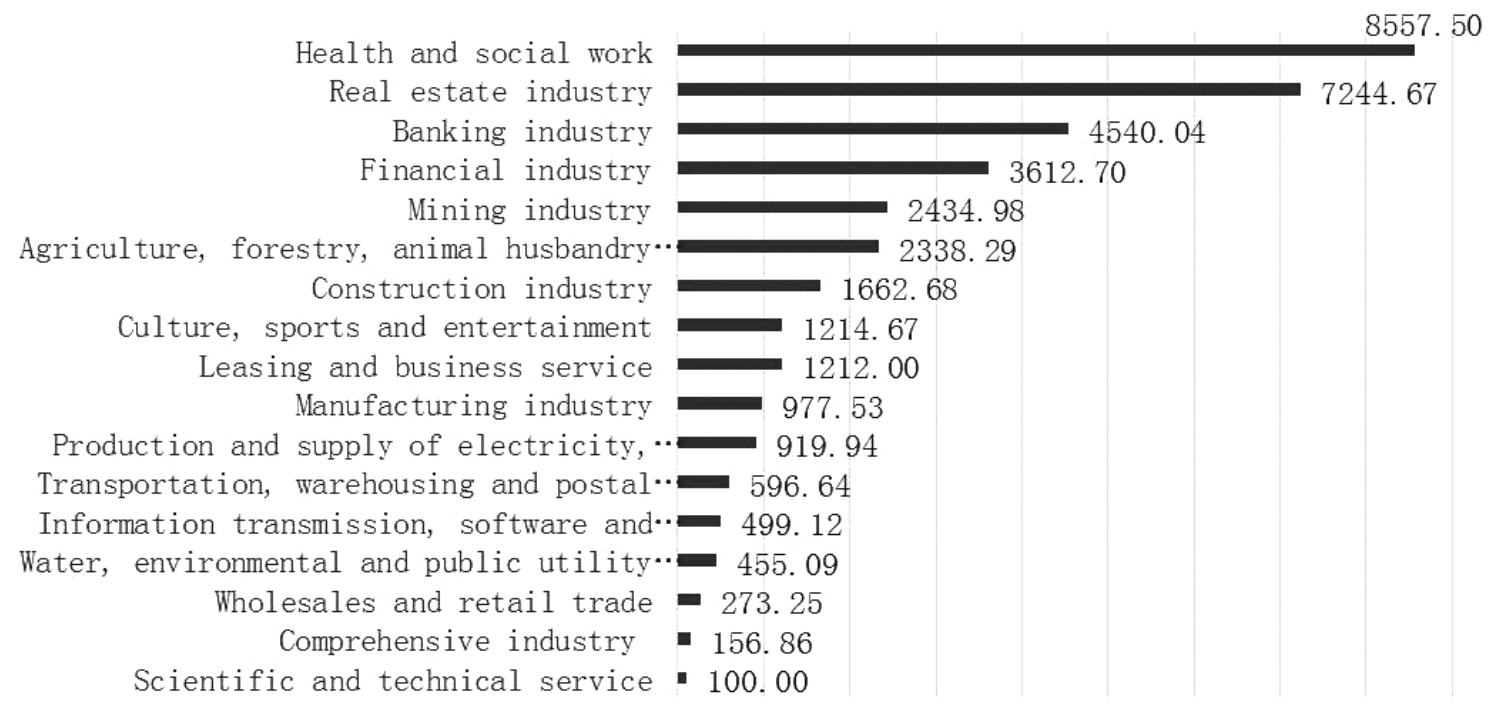

Data source: Manually organize the data disclosed in the social responsibility reports of listed companies

Figure 3. The average amounts of social endowment (2019) 


\section{Conclusi on, Experience and Issue of the Investigation}

From the perspectives of the public, practitioners, supervision data and industry data comparison, it can be observed that since China's reform and opening-up in 1978, the performance of the commercial bank in social moral obligations generally maintains at a satisfactory level. Commercial banks' operation in China has made significant contributions to the development of China's economy and the people's livelihood. Their behaviors and activities are relatively active in demonstrating socialist morality and the core value system. According to the investigation and research, it is a significant experience for the steady development of commercial banks in China to strengthen the leadership of the CPC, base on the requirements of socialism, adhere to the basis of profit and attach importance to the fulfillment of social responsibilities. The research results also show that these commercial banks have some obvious problems, such as weak consciousness of moral obligation, deviation of ethical behavior, insufficient moral governance, and the inadequate guarantee of responsibility.

\subsection{Experience of Performing Moral Obligations by the Commercial Bank}

In the tide of reform and opening-up, the commercial bank in China has been developed by constantly fulfilling the country's moral obligations in aspects such as politics, economy, culture and society. Its great achievements gained are closely related to the reforms of China's political and economic system and the policy guidance, as well as the courage to assume their social responsibility and the efforts to carry out socialist moral practices.

(1) Firmly uphold the leadership of the ruling party. The socialist system with Chinese characteristics determines that the commercial bank in China must follow the road of development of banks with Chinese characteristics. "Strengthening the party's leadership over financial work" is the CPC's political stance on financial work. The party's management of finance is determined by the systemically important status of commercial banks, as well as by the fact that commercial banks are state-controlled, state-owned or supported by national policies. For commercial banks, firm support for the Party's leadership is embodied in supporting the Party's political program, carrying out the Party's principles and policies, implementing the Party's opinions and decisions, and constantly improving the party organization construction of the banking system. Thanks to the leadership and policy support of the ruling party, China's commercial banks have made great progress in terms of scale and efficiency over the past four decades.

(2)Base on the essence of socialism. Commercial banks in China constantly grow and thrive along with the development of the socialist market economy. It is an important development experience for China's commercial banks to base on the requirements of socialism and to standardize the operation of bank capital in the ethical framework of serving the people. Commercial banks actively implement state regulation policies to ensure economic and financial security and the stable development; give full play to the main functions, rationally allocate monetary and credit resources to promote social and economic prosperity and stability; provide financial assistance to support national infrastructure and livelihood projects; develop inclusive finance and support the sound development of agriculture, rural areas and rural residents as well as small, medium-sized and micro businesses. Special loans are granted to support public welfare undertakings such as "education", "medical care" and "charity". These are all correct responses of the commercial bank to the requirements of socialism.

(3) Adhere to the foundation of gaining profits. Profit is the source of the robust economic foundation of commercial banks and the foundation for their survival and development. Commercial banks must be market-oriented, continuously improve their service quality to win clients' trust, innovate their products and business models to succeed in market competitions, and continually improve their modern management mechanism to improve business performance. Commercial banks' adherence to profit as the foundation is a concrete manifestation of implementing socialist economic construction as the center. It fully reflects the decisive role of the market in the allocation of banking resources, effectively stimulates the internal vitality and driving forces of the banking system, and significantly improves the banks' operating efficiency. 
(4) Attach importance to the performance of social responsibilities. The high social moral obligation evaluation of commercial banks in China highlights their excellent images in social morality. Commercial banks are the product of social development, and their social attributes determine that they must fulfill corresponding social responsibilities. Active fulfillment of social obligations is the soil for commercial banks to survive and prosper. It is also a prerequisite for commercial banks to carry out global business. The development of their globalization relies on an active commitment to local social responsibilities and full respect for local politics, economy, culture, society, resources, and environment. It is the premise of modernization and globalization for commercial banks to pay attention to the fulfillment of social responsibility and improve the governance of social moral obligation.

\subsection{Issues in Performing Moral Obligations by the Commercial Bank}

(1)The sense of moral obligation is too weak. Combined with the survey data, it can be seen that problems such as discrimination against clients and regions, stingy service dedication, practitioners' favoritism and fraud, and insufficient disclosure of responsibility reports still exist generally in commercial banks in China. To some extent, these present situations reflect the indifferent attitude of commercial banks towards moral obligations. The following three aspects are mainly selected for discussion. First is the issue of discrimination against clients and regions that frequently take place in commercial banks. For example, the density of bank outlets in developed areas is significantly higher than in less developed regions. Banks even try to reduce costs by removing branches in less developed regions, making people living there face the dilemma of financial exclusion. Second is about practitioners' favoritism and fraud. For a long time, the cases of practitioners' favoritism and fraud in China's commercial banks show a tendency of frequent occurrence. In 2017 alone, the CBRC investigated and dealt with 1,547 persons in charge, and 167,000 cases of accountability were handled within banking institutions. ${ }^{[1]}$ Commercial bank employees are the group closest to money and bank capital. Under the influence of self-interest, money worship and opportunism, a few practitioners take risks, practice favoritism and abuse their power for personal gain because they have a large amount of personal information about their clients. From stealing customers' information to misappropriating customers' funds, illegally selling financial products, and even defrauding huge loans, there are almost all kinds of common moral hazard cases of banks in which employees practice favoritism and fraud. It reflects the indifference of the moral obligation consciousness of a few practitioners. The next is about the issues revealed in reports of social responsibility. Since the Shanghai Pudong Development Bank issued China's first bank social responsibility report in 2006, all major commercial banks in China have issued social responsibility reports. The social responsibility reports issued by many commercial banks generally reflect such problems as boasting reports, acting differently from the slogan of moral responsibility, showing more qualitative description and less quantitative explanation, displaying more positive content and less harmful content, and lacking objectivity in some substances.

The discrimination against customers and regions, the favoritism and fraud of practitioners, and the inadequate response of social responsibility report all reflect the lack of moral obligation consciousness of commercial banks. It is said that there is no commercial bank in the world that does not detest the poor and love the rich because the commercial bank is not a charity institution. It not only needs to make profits but also needs to consider the capital security and income of depositors. This is the defensive logic used by commercial banks when they are morally criticized. It is the operating principle of commercial banks in capitalist countries to regard the operation purpose as profit-seeking. Under socialism with Chinese characteristics, commercial banks should not only pursue profits but also meet the moral requirements of serving the people. It is immoral for commercial banks to be extremely utilitarian, mercenary, and even go against the essential requirements of socialism.

(2) There are deviations in moral obligation behaviors. The moral behavior of commercial banks is influenced by internal and external factors, including internal factors such as behavioral motivation, operational mechanism, overall quality of practitioners, policies, and regulations, social environment, global e- 
conomic and financial situation, and other external factors. In the investigation, it is found that behavioral awareness problems such as "the purpose of banks is to make money" and "duty stops at slogans" have weakened the commercial bank's behavioral ability to fulfill social moral responsibilities. A few bankers take advantage of their positions to occupy and embezzle customer funds and conduct favoritism and irregularities, which erode the image of moral responsibility of the commercial bank. Bank customers' unethical behaviors such as "dishonesty", "loan fraud", and "extreme utilitarianism" affect the performance of the bank's moral responsibility. The unreasonable bank policy and system mislead the commercial bank in the wrong way of morality. Among them, the most significant deviation of commercial banks in China is the alienation of their functions. The social function alienation of commercial banks is the phenomenon and tendency that they deviate from their business objectives and social values in corresponding business activities. The following is to examine the functional alienation of commercial banks from the perspectives of avoiding the reality of bank capital and dissolving human subjectivity. First, we can see the alienation of commercial banks from the perspective of avoiding the reality of bank capital. The investment and financing activities of commercial banks in pursuit of monetary appreciation are easy to induce the financial bubble, which leads to the phenomenon of capital idling when bank capital deviates from the real economy. We can take the real estate market in China's first-tier cities as an example. From 2007 to 2017, the housing price growth rate in Beijing, Shanghai, Guangzhou, and Shenzhen exceeded $15 \%$ annually, far higher than the growth rate of personal income. The real estate bubble at least caused the real economy to suppress the real economy's consumption demand and strike the enthusiasm of capital to invest in the real economy. The real economy is depressed and the virtual economy is full of bubbles, which will inevitably accumulate systemic financial risks and even lead to the economic and financial crisis. Finally, the commercial bank with the purpose of capital multiplication will also suffer significant losses or even bankruptcy. Second, we can see the alienation of commercial banks from the perspective of human subjectivity being dispelled by capital. The commercial bank is an economic organization permitted by the state to be established following the needs of social development. It is the fruit of human civilization, organized by, controlled by and serve the people. However, the reality is that a growing number of people are enslaved and controlled by bank capital. As consumers, people are enslaved by mortgage loans, house loans, car loans, consumer loans, etc. As practitioners, people are controlled by issues such as how capital increases in value and how to create higher profits through the capital operation. As shareholders, due to the phenomenon of objective factors of diversified property rights, under the system designed by the hypothesis of rational "economic man", the "social man" attribute of shareholders is submerged. In this context, people's subjectivity has been dispelled. In contrast, "capital", the subjectivity of commercial banks' operating object, has been highlighted continuously, and tends to become the mandatory power ruling everything.

(3) The governance of moral obligations is insufficient. The governance structure of commercial banks' moral obligations involves macro, medium, and micro levels. The macro level means the policies and regulations of commercial banks. The middle level consists of the operation and management, and the micro level includes specific business practices. Strictly speaking, China's commercial banks do not have a particular governance system for moral obligations. However, the Regulatory Department of CBRC, the Prudential Regulation Bureau, the Self-regulatory Committee of the China Banking Association and the Legal Compliance Department of the commercial bank, to a certain extent, play the role of governing social moral obligations of commercial banks and assume the task of bank moral obligation governance. From the perspective of the work carried out by various departments and information disclosure, the moral obligation governance structure of China's commercial banks is in a single structure that mainly focuses on the implementation of policies, laws, and regulations. Although government departments, banking associations, and regulatory bodies have put forward relatively general requirements on commercial banks' moral obligations, their initiative to fulfill the affirmative responsibility and mission responsibility is still insufficient. Taking the phe- 
nomenon of banks' reluctance to loan to small and micro enterprises as an example, for a long time, the low conversion rate of commercial banks from "dare not to invest, will not invest, and reluctant to invest" to "dare to lend, can lend, and will lend" reveals that the moral obligation governance system of commercial banks needs to be improved, and the strength of governance needs to be strengthened. The level of moral obligation governance in commercial banks is at the primary level of Gertrud Nunner-Winkler's theory of moral hierarchy. The responsibility expressed by the prohibition of "no" has not reached the moral realm of the affirmative responsibility represented by the moral code of "should" and the moral field expressed by the "mission".

(4) The protection of moral obligation is insufficient. At present, the moral obligation protection system of China's commercial banks mainly consists of the policy guidance documents related to social responsibility issued by the Central Bank, the Banking and Insurance Regulatory Commission and industry associations, such as the Opinions on Strengthening Social Responsibility of Financial Institutions in the Banking Sector issued by CBRC at the end of 2007, and the Guidelines on Corporate Social Responsibility of Financial Institutions in the Banking Sector approved and passed by China Banking Association in 2009. The release of a series of guidance documents on social responsibility has improved the disclosure level of commercial banks' social responsibility information in China. However, it is still not enough to motivate and guarantee the commercial bank to fully and actively fulfill social moral obligations. Commercial banks still generally have a weak sense of moral responsibility, inadequate implementation of social responsibility, improper behavior of employees, incomplete disclosure of social responsibility reports, insufficient authenticity and reliability, and many other issues. As for the morally inadequate phenomenon conducted by commercial banks such as standard window service discounts, outlets removal in less developed areas, the reluctance of loaning to small and micro enterprises, from the perspective of rational-economic man, it is an effective means to reduce the operating cost of banks and improve the working efficiency. From the standpoint of socialist morality, these behaviors violate the moral requirements of serving the people. Therefore, the guarantee system of commercial banks' moral obligations should not only take into account the purpose of their profitability but also banks' fulfillment of socialist moral responsibility. To coordinate the relationship between the interests of the broad masses of the people and the interests of the bank and continuously realize the unification of the benefits of the bank and the interests of the people is the direction of the construction of the moral obligation guarantee system of commercial banks.

\section{Suggestions for Improving the Current Situation of Performing Moral Obligations by the Commercial Bank}

\subsection{Elevating the Governance of Bank Moral Obli- gations to a State Strategic Level}

Elevating the governance of commercial banks' moral obligations to a state strategic level is determined not only by the importance of the commercial bank system but also by the moral obligation level of the commercial bank reflecting the country's governance ability and level of capital morality and the quality of the national system. Commercial banks are essential windows of the socialist market economy and have the moral guidance and demonstration effect for the entire market economy environment. As the core intermediary organization in the operation of the socialist market economy, the commercial bank should play a systemically important role and become the forerunner, pioneer, and advocate of the excellent social atmosphere. As the distribution center of monetary credit and capital, commercial banking is the watershed of the nature and superiority of socialism. The capital is the same. In a capitalist society, the capitalist controls the wage labor by the capital he commands and controls the social, economic, political, and cultural fields entirely. Capital serves the capitalists completely and finally shows itself as the bourgeoisie exploiting the proletariat and ruling the society. In a socialist society, capital is enjoyed by the people and is subject to state macro-control policies and the principle of distribution according to work. Relying on the shared prosperity of the people, capital serves the people and embodies a society where the proletariat takes charge and enjoys shared prosperity. "Justice and equality" is the core 
value standard of the socialist system. "Serving the people" to promote the interests of everyone is the core value of socialist morality. "Realizing the common prosperity of the people" is the essential requirement of socialism. Commercial banks serving the people is a critical embodiment of the essence and superiority of socialism.

Elevating the governance of commercial banks' social moral obligations to a state strategic level is a beneficial trial of correct moral anomie of commercial banks. It is a critical practice to strengthen the socialist moral obligation consciousness of the banks and further enhance the level of social moral responsibility. It is an essential means to implement the social value standard of "serving the people" of commercial banks. It is the political guarantee for commercial banks to fulfill their social moral obligations to lead the new trend of socialist morality in the new era.

\subsection{Enhancing the Sense of Moral Obligation of Commercial Bank Practitioners}

Lenin once said that there could be no revolutionary action without revolutionary theory. The understanding of the moral obligations of leaders and ordinary practitioners is the key to improve the level of moral obligations of the commercial bank. Leaders of commercial banks have more moral obligations on shoulders than ordinary practitioners because they hold more power. Leaders' moral obligation consciousness determines whether commercial banks' system is sound as well as the management goal and value function of commercial banks. The moral and conscience of the leader is the internal driving force for the commercial bank to fulfill social moral obligations. Strengthening the responsibility consciousness and moral quality of the leader is conducive to improving the commercial bank's ability to fulfill the social moral obligations. From a macro point of view, commercial banks are led by the Central Bank and regulatory authorities. From the micro point of view, the leaders of commercial banks are senior management decision-makers, such as the general meeting of shareholders, the board of directors and board of supervisors of commercial banks, as well as managers of departments at all levels. The key to improving the moral obligation consciousness of commercial bank leaders is to strengthen the propaganda and education of the theory of the essence of socialism, ensure that leaders fully understand and recognize the responsibility requirements of the socialist moral system, and fully integrate the concept of social moral responsibility into the construction of corporate culture and bank systems, thus implementing and popularizing the excellent socialist moral standards. Ordinary practitioners of commercial banks are the concrete executors of commercial banks' strategies, plans, and operations. Their sense of moral obligation directly affects the level of commercial banks' fulfillment of social moral obligations. As for ordinary bank employees, they can improve their sense of morality and responsibility, political and disciplinary awareness, business and professional quality, and the consciousness of consciously resisting moral hazard through regular training of professional ethics and professional quality and continuous improvement of the working system.

\subsection{Completing the Supervisory and Security} Mechanism of Banks' Moral Obligation Behaviors

The improvement of commercial banks' moral obligations also depends on the corresponding intense supervision and guarantee system. In terms of ethical responsibility behavior supervision and guarantee mechanism, the world bank's ethics committee and officials' moral order can be used as references. We can set up moral arbitration commission within the banking system to launch moral audits to policies and systems such as national fiscal and monetary policies as well as bank regulations, to ensure that the order of laws and regulations of the banking system conforms to social ethics or enjoys the leading and exemplary position in social moral obligations. We can regularly evaluate the social moral obligation behaviors of commercial banks and take the evaluation results as an essential basis for reward, punishment and supervision. We can realize the moral arbitration of major strategies, decisions, rules, and regulations within commercial banks to abandon the implementation of decisions, systems, and behaviors with ethical risks or potential adverse social effects.

In the supervision mechanism of commercial banks performing moral obligations, we should take the stand of the ethical principle of the socialist market economy with the unity of justice and interests, make full use of the reward and punishment mechanism of 
bank supervision, and correct the misunderstanding that deems maximizing economic profits as the only essence of banks. We should extend the control over the legal compliance and risk prevention of commercial banks to the supervision over the moral obligation behaviors, to avoid the phenomenon that departments at all levels turn a blind eye to commercial banks' self less dedication to create social value or blind pursuit of profits to harm social interests. Commercial banks' behavior to improve people's well-being through science, technology, and business innovation is encouraged. In contrast, their social functional alienation behavior, namely, "using capital to conceal the subjectivity of people", is resisted firmly.

In conclusion, the development of moral obligations of the commercial bank is a systematical project that necessarily requires the bank itself, the government, and the society to strengthen communication and in-depth interaction in the process of law-based governance and comprehensively deepening the reform. This is a process in which the commercial bank changes from the pursuit of a single economic value to the pursuit of a win-win situation for both financial and social values, and also a process to ensure that the commercial bank's consciousness on moral responsibility behavior keeps in line with the mainstream socialist ideology and keeps improving with the new era. As for the improvement of the moral obligation level of the commercial bank, on the one hand, it cannot be discussed without interests; otherwise, the commercial bank will leave the foundation of existence, and moral responsibility will only mean nothing eventually. On the other hand, the commercial bank's liability should not be limited to interests, especially economic bene fits, because this will only aggravate the moral and functional alienation of the commercial bank, leading to the prevalence of money worship and extreme utilitarianism. While reasonable profits of the commercial bank are respected, the commercial bank is encouraged to set up the noble socialist moral ideal, and continuously realize the coordinated development of economic and social value. This is the way of sustainable development for commercial banks.

\section{References:}

[1] China Bank Association, China Banking Development Report (2018): 13.

[2] WANG Bo, Nature and Logic of Capital in Marx's Eyes. Journal of the University of South China (Social Science). 2015(2), 21-25.

[3] NIE Hui, The Motivation, Present Situation and Countermeasures of China's Commercial Banks to Fulfill Their Social Responsibilities. Reform and Opening-up. 2016(08): 59-60.

[4] SHU Langen \& YU Liang, Formation Mechanism and Preventive Path of Moral Hazard in Commercial Banks. New Finance. 2005(4):33-36.

[5] TONG Shijun, The "Trend of Civilization" of Capital and Its Inherent Limitations. Academic Monthly. 2006 (10): 19-24.

[6] LI Yixian, Marx's Theory of Alienation and the Theory of All-round Human Development. Education Studies. 1981 (10):37-41.

[7] WANG Shuguang, Financial Ethics. Peking University Press, August 2011.

[8] Aloy Soppe.New Financial Ethics:A Normative Approach [M].University in Rotterdam,Netherlands.2016.

[9] Richard B. Brandt. Morality, Utilitarianism and Rights[M]. Cambridge University press, 1992. 